Research Article

\title{
Determination of Combustion Process Model Parameters in Diesel Engine with Variable Compression Ratio
}

\author{
Saša Milojevićc (iD) and Radivoje Pešić \\ University of Kragujevac, Faculty of Engineering, Department for Motor Vehicles and Motors, Kragujevac, 34000, Serbia \\ Correspondence should be addressed to Saša Milojević; sasa.milojevic@kg.ac.rs
}

Received 1 February 2018; Revised 22 May 2018; Accepted 28 June 2018; Published 7 August 2018

Academic Editor: Kalyan Annamalai

Copyright (C) 2018 Saša Milojević and Radivoje Pešić. This is an open access article distributed under the Creative Commons Attribution License, which permits unrestricted use, distribution, and reproduction in any medium, provided the original work is properly cited.

\begin{abstract}
Compression ratio has very important influence on fuel economy, emission, and other performances of internal combustion engines. Application of variable compression ratio in diesel engines has a number of benefits, such as limiting maximal in cylinder pressure and extended field of the optimal operating regime to the prime requirements: consumption, power, emission, noise, and multifuel capability. The manuscript presents also the patented mechanism for automatic change engine compression ratio with twopiece connecting rod. Beside experimental research, modeling of combustion process of diesel engine with direct injection has been performed. The basic problem, selection of the parameters in double Vibe function used for modeling the diesel engine combustion process, also performed for different compression ratio values. The optimal compression ratio value was defined regarding minimal fuel consumption and exhaust emission. For this purpose the test bench in the Laboratory for Engines of the Faculty of Engineering, University of Kragujevac, is brought into operation.
\end{abstract}

\section{Introduction}

City traffic and traffic flow have the greatest impact on the exhaust emission and air pollution, specifically in the street canyons, zones of city centers, etc. Moreover, in area of city traffic that can contribute substantially to declining of exhaust emission, by application of various methods. According to our practical experience, there are currently two real directions:

(i) To switch on alternative fuels, natural gas and hydrogen as clean driving energy, with parallel introduction of flexible transport which enables decrease of the number of vehicles in urban centers to avoid congestion [1] and

(ii) Further optimization of vehicles and conventional internal combustion (IC) engines by lowering internal friction and mechanical losses, in order to reduce fuel consumption and exhaust emission. This requires application of new materials and variable mechanisms on (IC) engines, such are variable compression ratio (VCR), variable valve train (VVT), fuel injection systems with variable injection timing that have the capability of split multi-injections, homogeneous compression ignition combustion (HCCI), controlled autoignition (CAI), etc. [2-5].

Mechanical efficiency of the (IC) engines and generally reciprocating machines is dependent by energy losses associated with friction, i.e., the conditions inside tribological system which consisting of piston, piston rings, and cylinder liner. Generally, mechanical efficiency lowers in case of raising the compression ratio (CR) and opposite [3-5].

With reciprocating machine optimization, by application of aluminum alloys and aluminum metal-matrix composites (MMC) for making of machine parts, we contribute to the lowering weight of engine and vehicle as well as friction and wear. Reduction of weight, friction, and wear of the vehicle and equipment contribute to the reduction of fuel consumption as well as exhaust emission [6-8].

VCR method is used to determine optimal (CR) for diesel engines under different loads $[9,10]$ in combination with other variable systems on engine, such are flexible intake valve actuation [11], exhaust gas recirculation (EGR) [12], and 

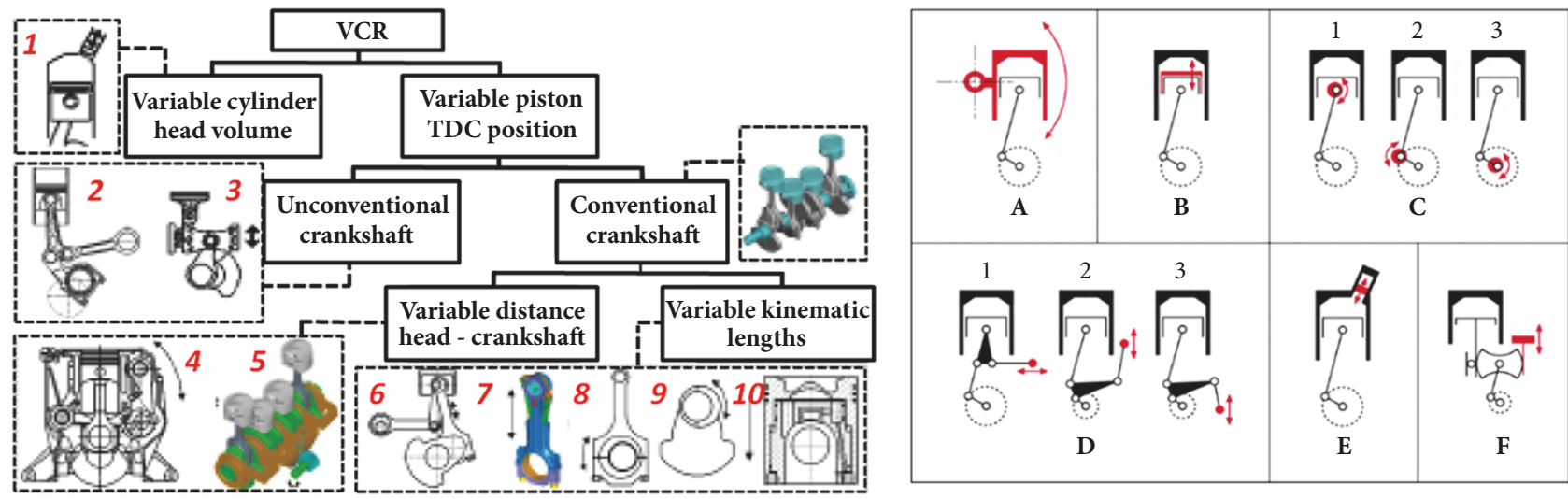

FIGURE 1: Classification of the various VCR mechanisms (an evaluation matrix). (a) VCR mechanism that adjust the clearance volume without modifying the (TDC) position: (1; E)-secondary piston for adjust the clearance volume; 4 ; A)-cylinder moves up by rotation; (10)-cylinder moves up by translation; (b) VCR mechanism that adjust the clearance volume by modifying the (TDC) position: (2, 6, 7; D)-linkage; adjust base pivot or link length; (3; F)-rocking, movement on one side generates opposite movement in piston; (B)-elastic components compress at higher pressures thus reducing clearance volume and reducing compression ratio at higher loads; (8, 9; C)-eccentric pivots; effectively adjusts link lengths.

variable fuel injection time $[13,14]$. Generally, with integrated system for (VCR) it is possible to increase engine efficiency, power, and torque; the engine can to operate under multiple cycles with multifuel capability, i.e., well adjusting to knock limitations when use of various fuels.

According to our experimental results, in the case of application of alternative fuels in diesel engines, when using their mixtures with diesel fuel, (VCR) system is obligatory for optimal combustion and engine operation $[3,5,6]$. Some authors have studied the effect (CR) on performance and emissions of diesel engine operated with waste fried oil or neem methyl ester blend $[15,16]$ and Jatropha curcas Ethyl Ester Blends [17]. Biodiesel as a fuel for diesel engines is very interesting, and its application in diesel engines also requires a mechanism for automatic change the (CR), to adapt the fuel to the conditions in the engine [18].

Application of gaseous fuels such as Hydrogen and natural gas as well as their mixtures is more interesting in gasoline engines and original gas engines with (VCR) than in diesel engines [19].

In area of transport vehicles and heavy-duty engines, as example, Caterpillar has developed (VCR) engine for homogeneous charge compression ignition (HCCI) combustion. As a result the 15 -liter engine with automatic compression ratio changes from 8 to 15:1 [20].

The main reason for the growth in engine modeling activities arises from the economic benefits; by using computer models, large savings are possible in expensive experimental work when engine modifications are being considered. Models cannot replace real engine testing but they are able to provide good estimates of performance changes resulting from possible engine modifications and thus can help in selecting the best options for further development, reducing the amount of hardware development required. While the more advanced models are extremely large and complex, the basics of an engine thermodynamic model are quite straightforward and easily understood; the complexity arises later in the refinement of the calculation methods, the level of detail of subsystem representation, and the accommodation of a wide variety of alternative engine configurations and control systems.

The authors have also successfully studied the influence of CR on combustion process in experimental diesel engine. Validation of the results received by using the model of the diesel process with double Vibe function was carried out in parallel by their comparison with relevant results obtained during experimental measurements [3-5].

The main goal of the paper is to determine the influence of $\mathrm{CR}$ and engine working regimes on the combustion characteristics and shape parameters of double Vibe function, as well as, on the fuel consumption and exhaust emission. Detailed results of experimental measurements are presented in literature [5].

\section{Materials and Methods}

2.1. Overview of VCR Mechanisms. Numerous construction solutions of (VCR) engine and systems can be found in the literature. Certain constructions have been practically realized. VCR mechanisms can be realized with variable cylinder head volume or with variable position of piston top dead center (TDC), Figure 1. TDC piston position can be regulated by using an unconventional crank-train in combination with a two-piece connecting rod, which is controlled by an additional shaft, or by using a rack-andpinion gear for the transmission of power from the piston to the crankshaft. Alternatively, retaining a conventional crankshaft drive, the (TDC) piston position can be varied by modifying the distance between the crankshaft and the cylinder head or by varying the kinematics effective lengths of the crankshaft drive. The distance between the crankshaft and the cylinder head can be changed by tilting the cylinder head together with the cylinder barrel relative to the bearing pedestals, or by means of a translator mechanism acting 


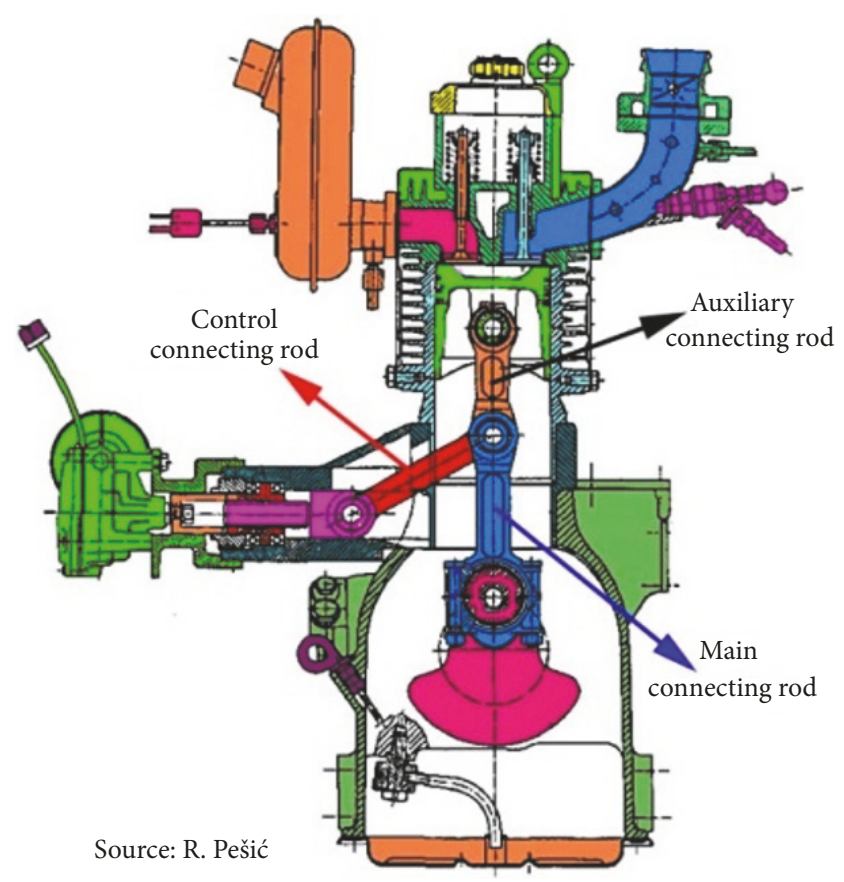

(a)

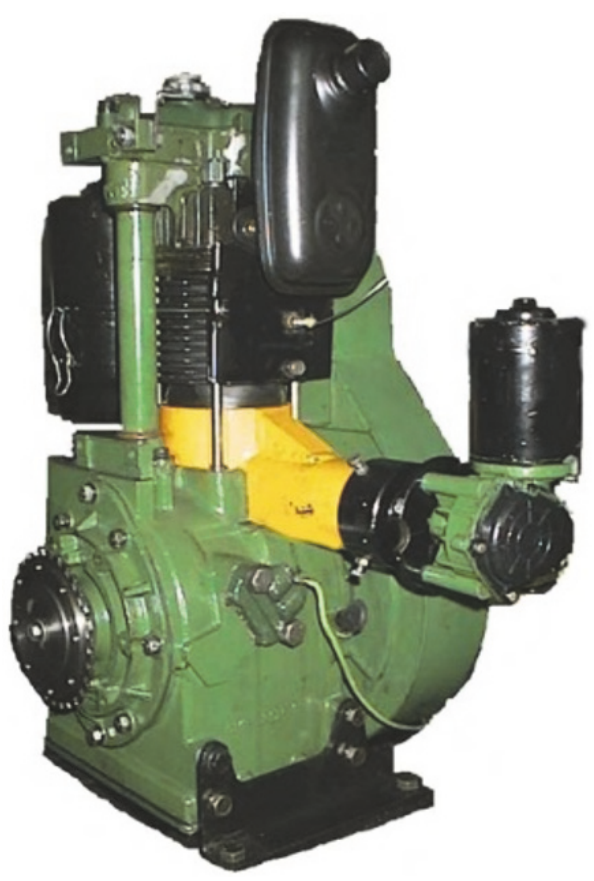

(b)

FIgURE 2: (a) Cross section and (b) photography of the experimental engine with VCR mechanism.

on the cylinder head and barrel unit. The required distance change can be realized also by utilizing an eccentrically supported crankshaft. The variation of cinematically effective lengths opens up the widest range of constructive possibilities: compression height, connecting rod length, and crank radius can be modified by means of eccentric bearings or by using a linear guidance device [21-23].

Taking into account technological possibilities and economic demands we have developed experimental engine with automatic mechanism with two-piece connecting rod (threeconnecting rod) for adjusting the clearance volume, Figure 2 [3]. The auxiliary control mechanism for automatic (CR) change includes Electronic Control Unit (ECU) and control rod, both connected with scroll gear mounted like linking.

Developed (VCR) engine with three-connecting rod mechanism can be used in all modern diesel and gasoline engines in which the VCR is applied in order to optimize the efficiency.

2.2. Experimental Setup. The experiments were carried out in the Laboratory for Engines of the Faculty of Engineering, University of Kragujevac (FIN). A single cylinder, four-stroke, and air cooled diesel engine, maker DMBLombardini type 3LD450, was used during experiment (direct fuel injection, $6 \mathrm{~kW}$ power, bore $80 \mathrm{~mm}$, and stroke $85 \mathrm{~mm})[4,5]$.

The geometric value of $\mathrm{CR}(\varepsilon)$ is varied from 17.5 to 12.1:1 by replacing the pistons with different piston bowl volume (realized by changing the piston bowl diameter from 43 to $55 \mathrm{~mm}$ ). It is well known that the piston bowl geometry design affects the air-fuel mixing and the subsequent combustion
TABLE 1: Fuel characteristics.

\begin{tabular}{lc}
\hline Description & Values \\
\hline Cetane number $(\mathrm{CN})$ & 52 \\
Specific density at around $20^{\circ} \mathrm{C},\left(\mathrm{g} / \mathrm{cm}^{3}\right)$ & 0.839 \\
Kinematic viscosity at around $20^{\circ} \mathrm{C},\left(\mathrm{mm}^{2} / \mathrm{s}\right)$ & 3.964 \\
Sulphur content $(\%)$ & 0.5 \\
\hline
\end{tabular}

and pollutant formation processes in a direct injection (DI) diesel engine. In this paper, all investigations results were solely related to the CR.

During the experiments, the engine was operated with standard diesel fuel with characteristics specified in Table 1 $[4,5]$.

The test rig is equipped with the measuring and data acquisition system, Figure 3. Various sensors are mounted on the engine to measure different parameters. A thermocouple was installed on the surface of high pressure fuel pipe. A precision crank angle (CA) encoder was coupled with the crankshaft of the engine. The software stores the data of pressures and volumes corresponding to a particular (CA) location for plotting the indicator diagram curves. The cylinder pressure is measured using the (AVL QC32D) water-cooled piezoelectric transducer. The signal of pressure is amplified with the (Kistler 5007) charge amplifier and it was processed by using the (AVL IndiCom Indicate Software Version 1.2) [5].

The software provides the facility of analyzing the combustion data such as the rate of heat release, ignition delay, 


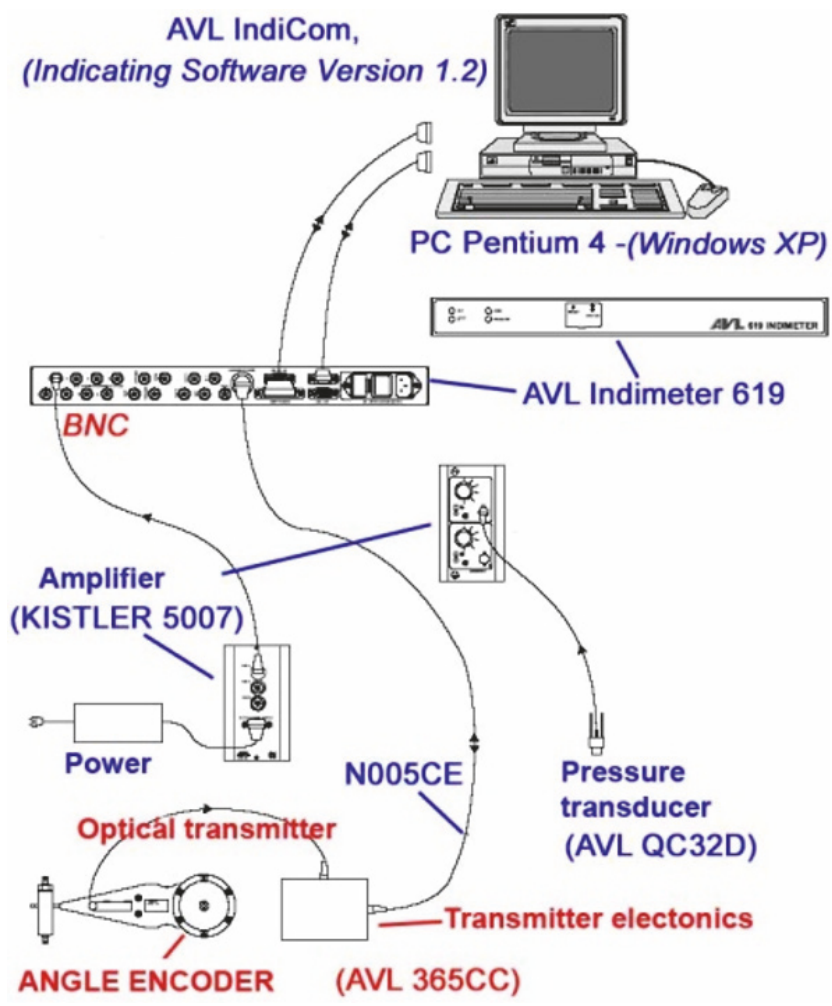

FIGURE 3: Schematic diagram of the experimental setup.

combustion timing in degrees, and peak pressure and stores them separately for analysis in the data acquisition system.

The experimental engine is tested on the (SCHENK U116/2) engine dynamometer. Tests are carried out at CRof $(12.1,13.8,15.2$, and 17.5:1). Working regimes for fuel consumption and exhaust gas analyse are defined according to the European Stationary Cycle (ESC) 13-mode cycle. Specific emission of exhaust gases is calculated using the obtained data of exhaust emission and measured engine power at corresponding working point. The final emission results are expressed in $\left(\mathrm{g} \cdot \mathrm{kW}^{-1} \cdot \mathrm{h}^{-1}\right)$, [5].

Exhaust gaseous is analysed with measurement equipment type (AVL Dicom 4000). Particulate matter (PM) emissions are determined indirectly through the empirical correlation between the measured values of smoke and PM. The smoke is measured using the (AVL 409) equipment according to method BOSCH [3-5].

\section{Result and Discussion}

\subsection{Modeling of the Combustion Process at Diesel Engines Having VCR}

Theoretical Analysis. The combustion characteristics can be compared by the means of cylinder gas pressure, rate of heat release, ignition delay, etc.

The normalized heat release rate (NHRR) is an important parameter to analyze the combustion process in the engine cylinder. The important combustion process parameters such

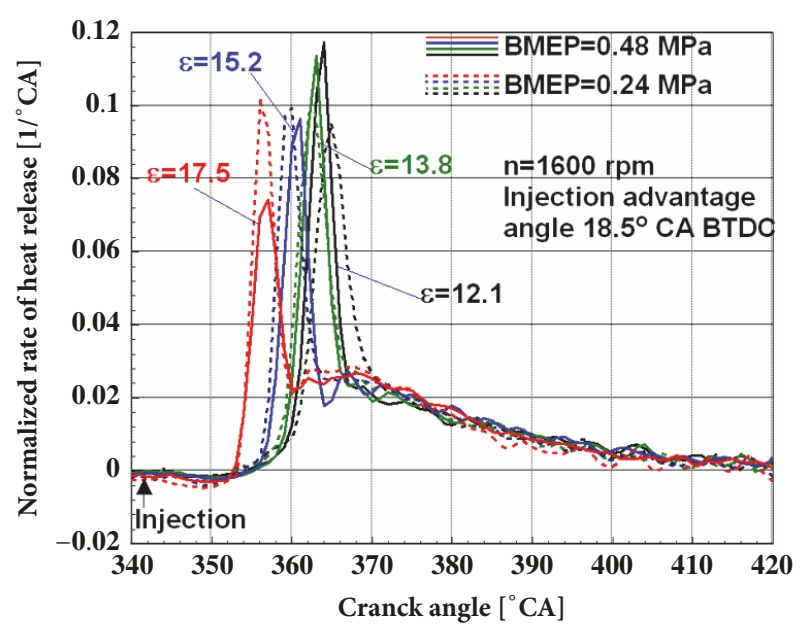

(a)

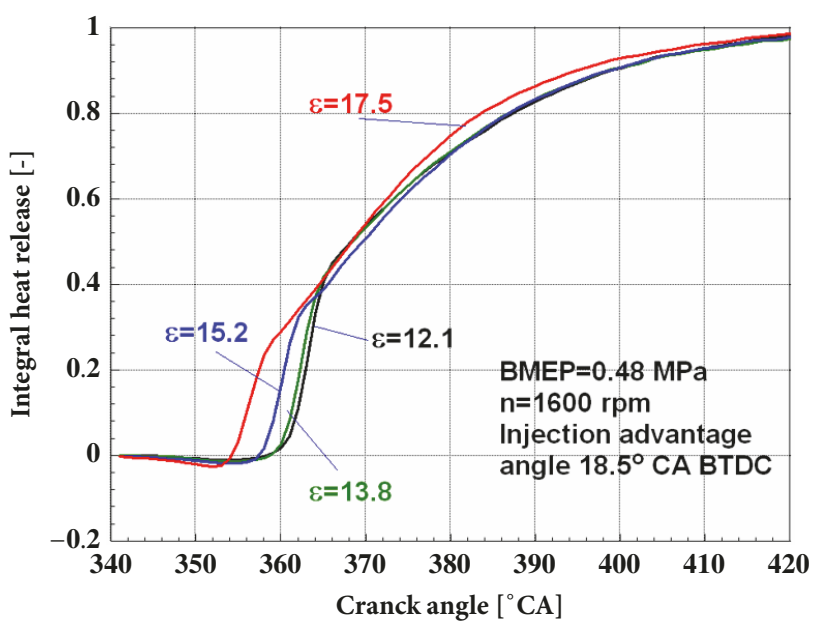

(b)

FIGURE 4: (a) Normalized rate of heat release during combustion and (b) integral heat release vs. crank angle.

as combustion duration and intensity, for different engine load (BMEP: brake mean effective pressure), could be easily estimated from the rate of heat release diagram, Figure 4.

On analysed engine regime the ignition delay period is too longer when the engine works under lower (CR) value. The longer ignition delay period results in a higher proportion of the injected fuel remaining unburned. The large accumulation of unburned fuel during the ignition delay period leads to a characteristics sharp peak, Figure 4(a). At moderate decrease of $\mathrm{CR}$ at higher loads $(\mathrm{BMEP}=0.48 \mathrm{MPa})$, the decrease of maximal cylinder temperature occurs. During further decrease of the CR, the maximal temperatures start to increase [5]. Explanation is in considerable increase of the combustion law maximum due to the increased ignition delay, Figure 4(a), induced by lower temperatures at the fuel injection timing. It leads to the increased amount of fuel burned during premixed combustion.

At low loads $(\mathrm{BMEP}=0.24 \mathrm{MPa})$, when the $\mathrm{CR}$ decreases, maximal values of the combustion law continually decrease, 
Figure 4(a), which reflects in the reduction of maximal cylinder temperature values [5].

Influence of the $\mathrm{CR}$ on the integral heat release or combustion efficiency is shown also on Figure 4(b). Change of combustion chamber shape, with the decrease of the CR, leads to certain reduction of the combustion efficiency.

In diesel engine, cylinder pressure depends on the burnt fuel fraction during the premixed burning phase, that is, initial stage of combustion. Cylinder pressure characterizes the ability of the fuel to mix well with air and burn condition. The experimental engine has an old fuel injection system with low injection pressure. Since we were not able to get a modern fuel injection system, we decided to do the testing with the existing fuel injection systems. Therefore, all the results have been obtained with a low injection pressure.

Vibe function is one of the most famous equations or functions that are used for modelling the combustion process in (IC) engines. Vibe function is often used to approximate the actual heat release characteristics of an engine. Integral of the Vibe function gives the fraction of the fuel mass that has been burned since the start of combustion.

In this paper is described the methodology of modelling combustion process, with purpose to see how the working regimes and (CR) value affect double Vibe function parameters [24]. If operation process of diesel engine with DI and premixed combustion is modeled, the use of double Vibe function is necessary [5]. At (DI) diesel engines with distinct explosive combustion and diffusive combustion, a model based on one Vibe function cannot describe the characteristic form of the combustion process. In that case, it is necessary to use a model based on superposition of two Vibe functions, one simulating the explosive part (index "1") and the other simulating the diffusive part (index " 2 "), as follows:

$$
\begin{aligned}
x_{1}= & \sigma_{g}\left[1-e^{-C\left(\phi_{1} / \phi_{z 1}\right)^{m_{1}+1}}\right] \\
\frac{d x_{1}}{d\left(\phi_{1} / \phi_{z 1}\right)}= & \sigma_{g} \cdot C\left(m_{1}+1\right)\left(\frac{\phi_{1}}{\phi_{z 1}}\right)^{m_{1}} \cdot e^{-C\left(\phi_{1} / \phi_{z 1}\right)^{m_{1}+1}} \\
x_{2}= & \left(1-\sigma_{g}\right)\left[1-e^{-C\left(\phi_{2} / \phi_{z 2}\right)^{m_{2}+1}}\right] \\
\frac{d x_{2}}{d\left(\phi_{2} / \phi_{z 2}\right)}= & \left(1-\sigma_{g}\right) \cdot C\left(m_{2}+1\right)\left(\frac{\phi_{2}}{\phi_{z 2}}\right)^{m_{1}} \\
& \cdot e^{-C\left(\phi_{2} / \phi_{z 2}\right)^{m_{2}+1}}
\end{aligned}
$$

Double Vibe function is expressed as the sum of the first and second part of the Vibe function:

$$
\begin{gathered}
x=x_{1}+x_{2}, \\
\frac{d x}{d \alpha}=\frac{d x_{1}}{d \alpha}+\frac{d x_{2}}{d \alpha}
\end{gathered}
$$

where

(i) $x$ : cumulative normalized heat released (mass fraction burned);

(ii) $\alpha$ : crank angle (CA); (iii) $\mathrm{m}_{1}, \mathrm{~m}_{2}$ : Vibe function shape parameter (for first and second function part);

(iv) $\phi_{1}, \phi_{2}$ : angle between initial and current time of the first and second Vibe function;

(v) $\phi_{\mathrm{z} 1}, \phi_{\mathrm{z} 2}$ : duration angle of the each simple Vibe function (duration of the heat release);

(vi) C: Vibe function parameter $(C=6.908)$; and

(vii) $\sigma_{\mathrm{g}}$ : share of fuel mass burnt during the first Vibe function (explosive combustion).

In order to establish the influence of the CR on the parameters of double Vibe function, corresponding experimental and theoretical investigations of the diesel engine with (CR) change were performed. The research results are shown in Figure 5. As can be seen, a good match between the model and experiment is achieved.

Variation of the identified combustion process parameters is presented in Figure 6 as function of the CR. The increase in CR at constant engine speed and load results in significant decrease of the Vibe function coefficient, Figures 6(a) and 6(b).

The tests have shown that duration angle of the first explosive part of the combustion is nearly constant, $\left(\Phi_{\mathrm{zl}}=9 \mathrm{deg}\right.$ $\mathrm{CA}$ ), and this value remained the same during modelling. The total duration angle of combustion, $\left(\Phi_{\mathrm{z} 2}=\Phi_{\mathrm{z}}\right)$, increases with the increase of CR, Figure 6(c). It is the consequence of the larger amount of fuel combusting with diffusive combustion, as shown in Figure 5.

The amount of the fuel burnt at the first explosive part of first Vibe function, $\left(\sigma_{\mathrm{g}}\right)$, significantly decreases with the increase of the CR by constant amount of the injected fuel and constant engine speed, Figure 6(d). It is also connected to a shorter period of ignition delay at higher CR.

Angle of initial (start) of combustion $\left(\alpha_{\mathrm{ps}}\right)$ under constant fuel injection timing $\left(\alpha_{\mathrm{pu}}=18,5 \mathrm{deg}\right.$ CA) intensively increases with the increase of the CR, due to shorter period of ignition delay, which is a consequence of higher maximal temperatures at the moment of fuel injection, Figure 6(e).

All tests were performed with experimental engine and conventional diesel fuel injection system: fuel supply pumppipe-fuel injector. Injection pressure was $20 \mathrm{MPa}$. Experimental engine with direct injection (DI) had two valves and fuel injector having 4-hole (nozzles).

3.2. Optimal Values of the Compression Ratio. The maximal pressure in cylinder $\left(\mathrm{p}_{\max }\right)$ and exhaust gas temperature $\left(\mathrm{T}_{\text {exhaust }}\right)$ as the function of engine load BMEP (or Wespecific effective work) for different (CR) values are shown in Figure 7.

With the increase of (CR) and engine load, under the same injection timing (18.5 deg CA) before top dead centre (BTDC), maximum cylinder pressure is increasing, too. This undesirable increase in $\left(\mathrm{p}_{\max }\right)$ is followed by a relatively improved atomizing of larger amount of fuel in cylinder under higher pressure and engine temperature. Because of improved conditions for combustion process, the entire working process is improved. Moreover, when the CR is increased, the $\left(T_{\text {exhaust }}\right)$ value is decreased, Figure 7 , as 

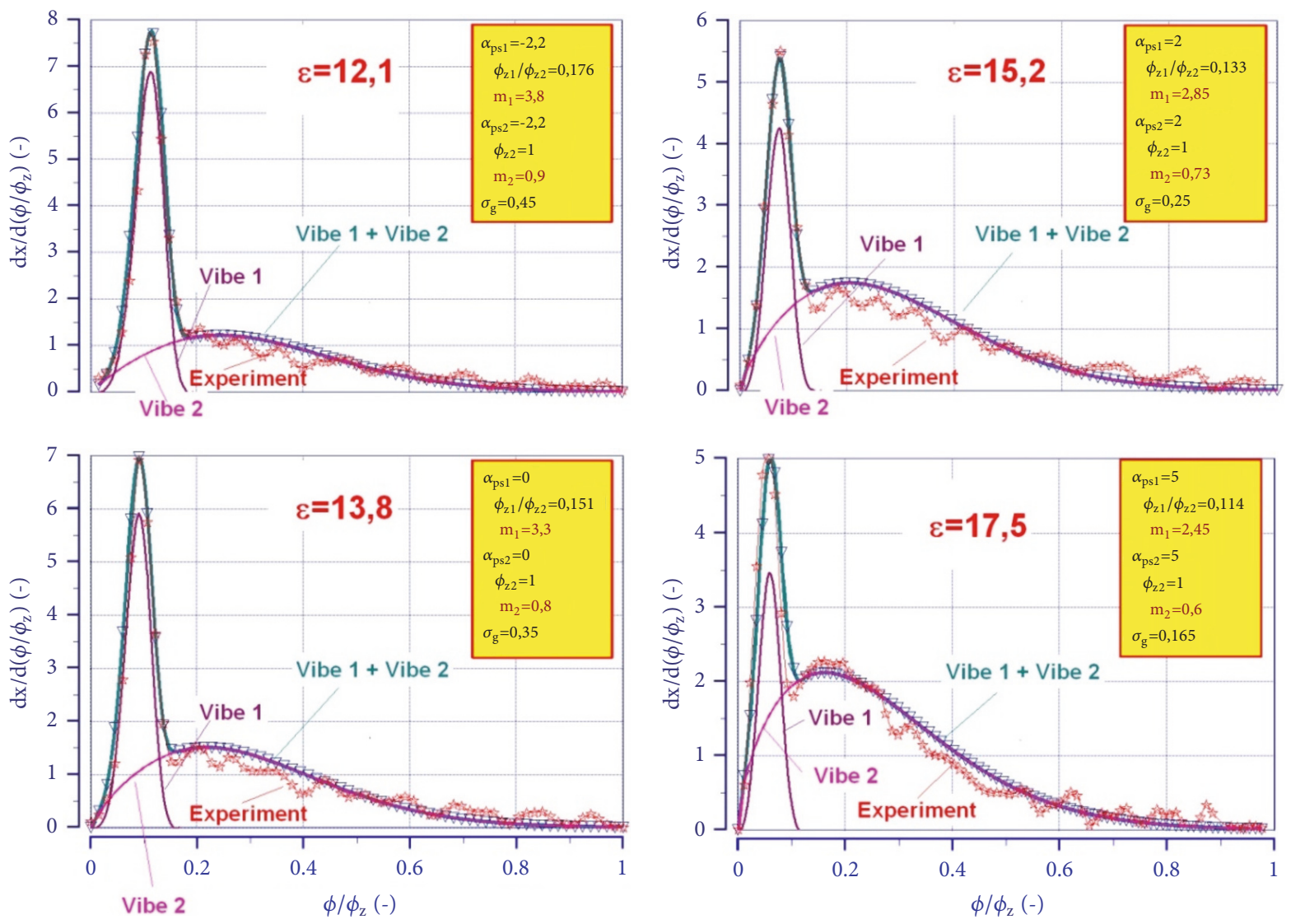

FigurE 5: Experimental and theoretical rate of heat release diagrams of experimental diesel engine under speeds of $\mathrm{n}=1960 \mathrm{rpm}$, fuel injection angle 18.5 (deg CA), BMEP=0.55 MPa. $\left(\alpha_{\mathrm{ps} 1}\right.$ and $\left.\alpha_{\mathrm{ps} 2}\right)$ are angle of initial (start) of combustion ( $2 \%$ of burned mass) for the first and second Vibe function, respectively.

revealed by simple isentropic relation at high $\mathrm{CR}$. Similar results can exist in literature [25].

Leaner air-fuel mixture is used in engine operation under low loads. Therefore, the amount of heat released during the combustion process is decreased. Also, the relatively low fuel injection pressure, which is very poorly dispersed, leads to the existence of large droplets of fuel. A consequence of this is certain decrease in temperature of the engine parts and decrease in cylinder temperature in the first phase of fuel injection. We can see also overlap of $\left(\mathrm{T}_{\text {exhaust }}\right)$ under middle (CR) values for all load regimes.

Dependence between the BSFC-brake specific fuel consumption and the CR is presented in Figure 8, for optimal injection time, at various load conditions.

The increase of the CR results in less intensive increase of the specific fuel consumption at low load conditions and, then, it more intensively increases for CR above $(\varepsilon=14)$, Figure 8.

At high load conditions, the fuel consumption first decreases and reaches the minimum value for compression ratio near $(\varepsilon=15)$ and then starts to grow again with further increase of (CR), Figure 8 . The increase of the engine speed causes the increase in the mechanical and aerodynamic losses and the increase in fuel consumption, Figure 8. The combustion process is responsible for increasing of the fuel consumption. This is obvious in the case of a combined application of low CR and shortened injection timing, when the delay of ignition becomes longer and, because of that, the combustion process is prolonged to expansion stroke. This is followed by a decrease in maximal pressure and temperature within a cylinder, while temperature during an expansion process shows a tendency to increase [5]. Because of that, the losses become greater and this may be followed by an increase in the specific fuel consumption.

The optimal value of the $\mathrm{CR}$ at which the engine has minimal fuel consumption increases with the increase of the load, Figure 9. At full load, minimal fuel consumption is achieved with $(\varepsilon=17.5)$, while at low load conditions, minimal fuel consumption is achieved with $(\varepsilon=12)$.

Under low and medium loads, the emission of $\left(\mathrm{NO}_{\mathrm{x}}\right)$ increases with the increasing of the CR, Figure 10. At high loads, the $\left(\mathrm{NO}_{\mathrm{x}}\right)$ emission firstly decreases and then increases with the increasing of the $\mathrm{CR}$ and reaches its minimal value for $(\varepsilon=15)$, Figure 10. Under higher loads, minimal $\left(\mathrm{NO}_{\mathrm{x}}\right)$ emission is reached with $(\varepsilon=15)$, Figure 11 .

In the case of the largest value of the CR under all loads, largest temperature occurs inside the engine cylinder. Large amount of free oxygen under low loads, in spite of relatively 


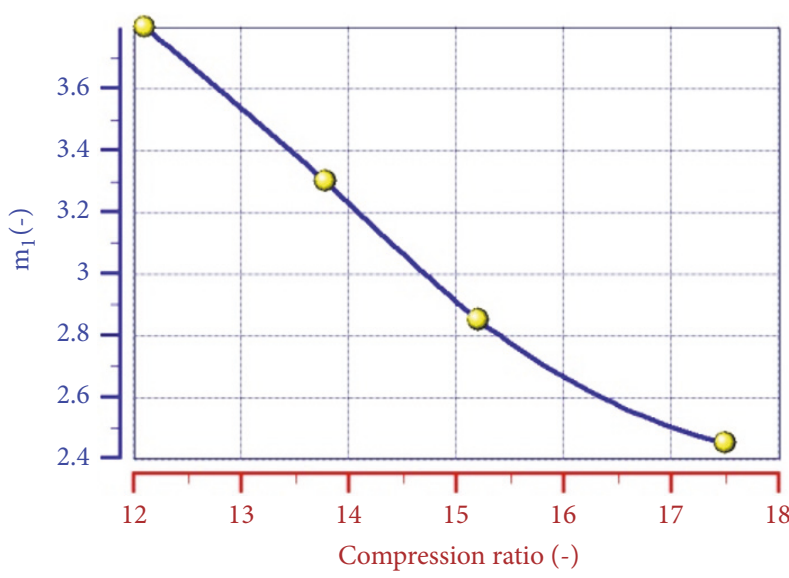

(a)

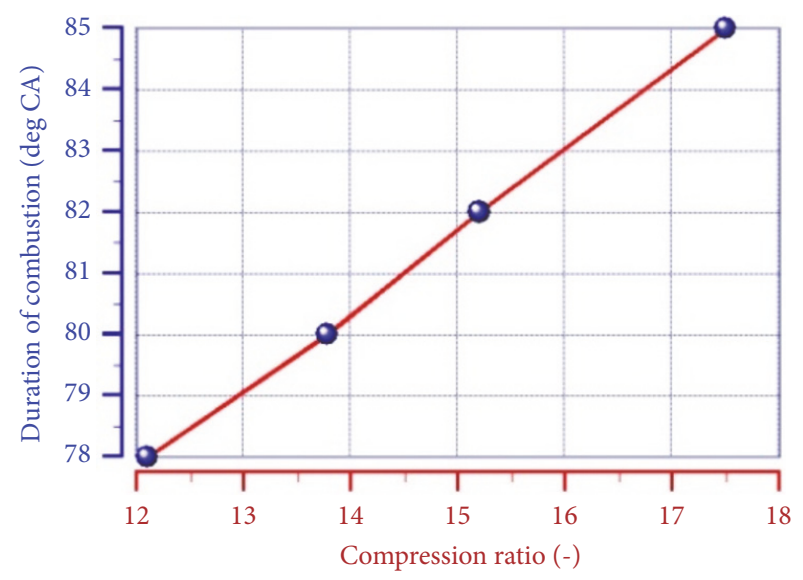

(c)

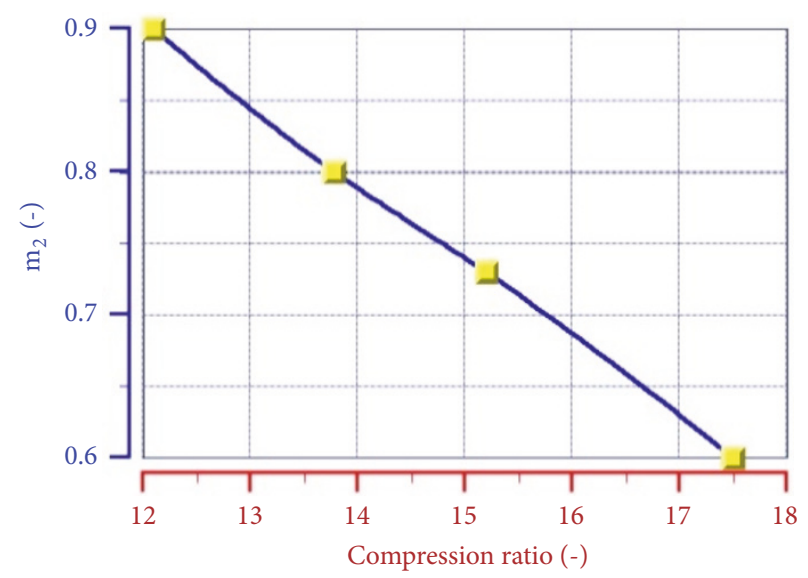

(b)

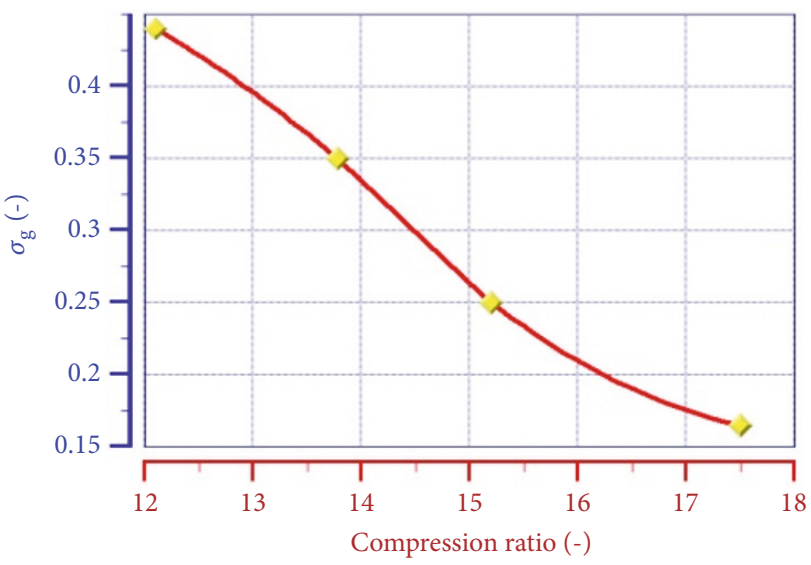

(d)

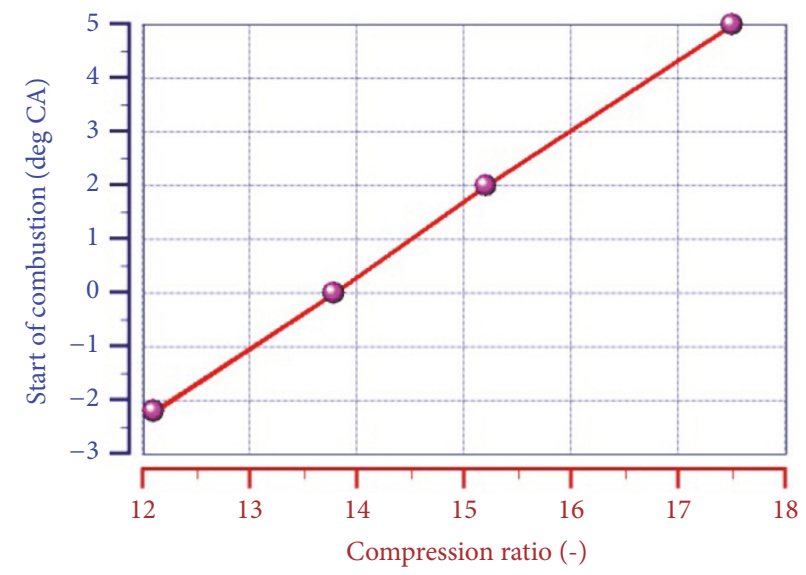

(e)

FIGURE 6: Model parameters variations as functions of the (CR) under $n=1960 \mathrm{rpm}$, injection advance angle 18.5 (deg CA), and $\mathrm{BMEP}=0.55 \mathrm{MPa}$

low maximal temperature with respect to full load, leads to formation of the largest amount of $\left(\mathrm{NO}_{\mathrm{x}}\right) \cdot \mathrm{NO}_{\mathrm{x}}$ emission decreases with load increase, under higher $C R$ value.

In the case of the lowest value of the CR under low loads, we have the lowest maximal temperature within the working cycle. This leads to formation of the lowest amount of $\left(\mathrm{NO}_{\mathrm{x}}\right)$.
With an increase in load, temperature increases as well and the amount of free oxygen decreases. Thus, at the beginning of the process, the amount of produced $\left(\mathrm{NO}_{\mathrm{x}}\right)$ increases but, when the amount of free oxygen decreases, a decrease in the amount of produced $\left(\mathrm{NO}_{\mathrm{x}}\right)$ would occur with load increase [5]. 


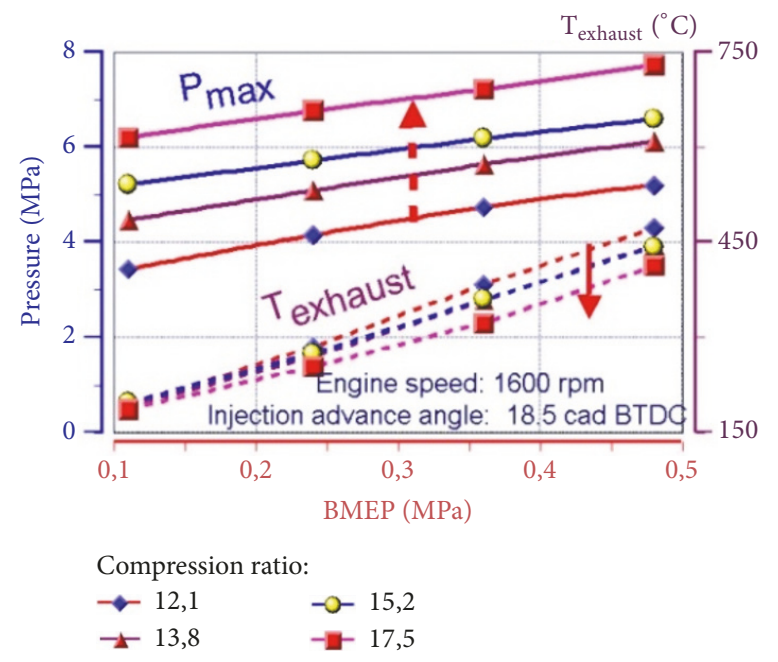

FIGURE 7: Cylinder pressure and exhaust temperature change in experimental diesel engine.
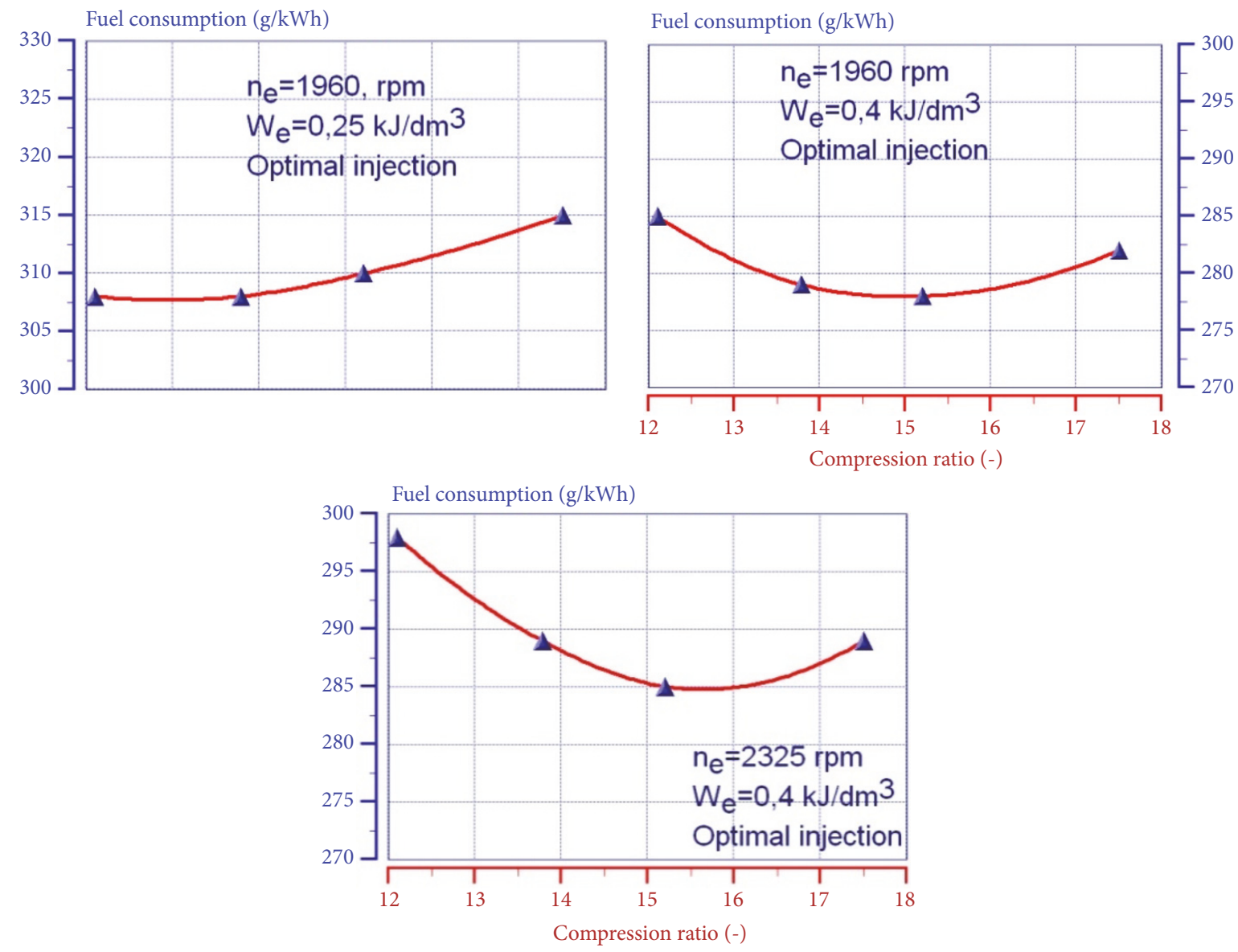

Figure 8: Influence of the (CR) on specific fuel consumption.

Particles emission (PM) is the smallest at medium loads and it increases if the engine is running at low or high loads. At the same time, (PM) emission increases with the increase of CR at all loads, Figure 12, so optimal CR is $(\varepsilon=12)$,
Figure 13. Generally, under very low loads, the (PM) emission is somewhat larger. The major reason for this is a relatively low injection pressure of the small amount of fuel that does not atomize so well. As the amount of fuel increases with a 


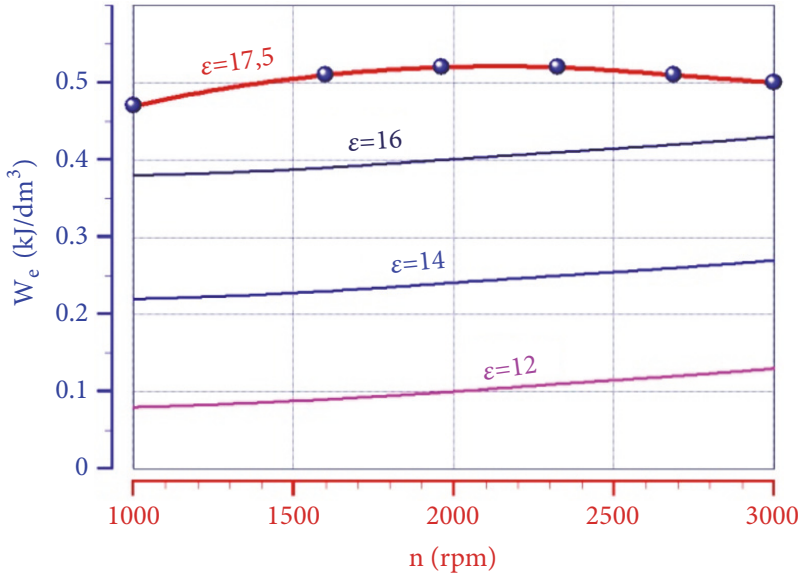

FIGURE 9: Selection of the optimal value of the (CR) for the engine operation with minimal fuel consumption.

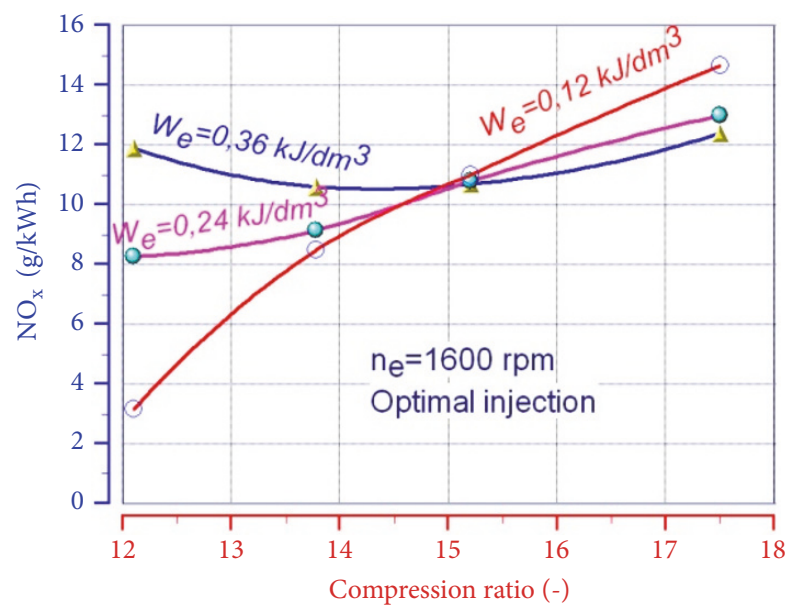

FIGURE 10: Influence of the (CR) on $\mathrm{NO}_{\mathrm{x}}$ emission.

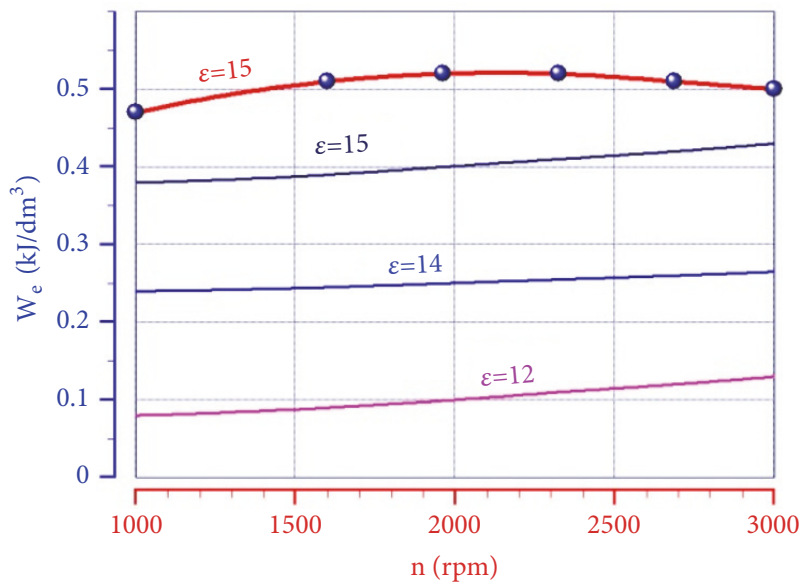

FIGURE 11: Selection of the optimal value of the (CR) for engine operating with the minimal $\mathrm{NO}_{\mathrm{x}}$ emission.

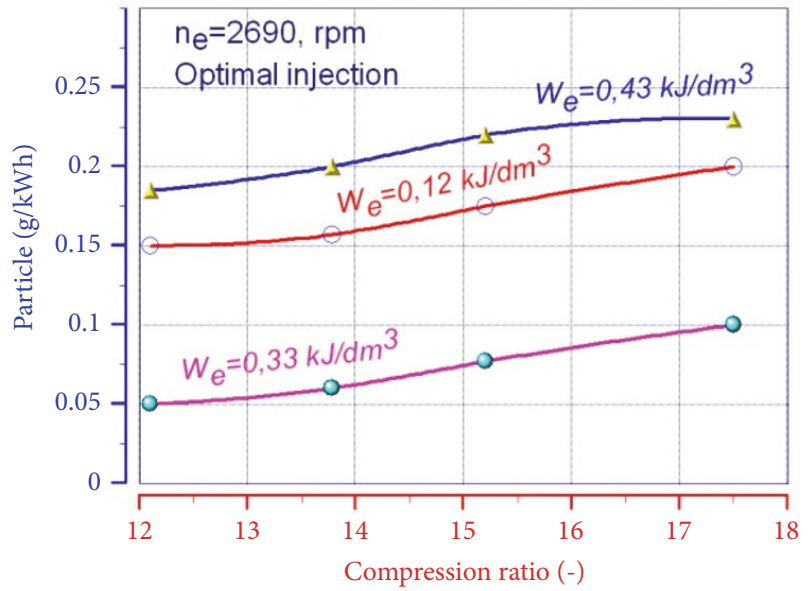

FIGURE 12: Influence of the (CR) on particles emission.

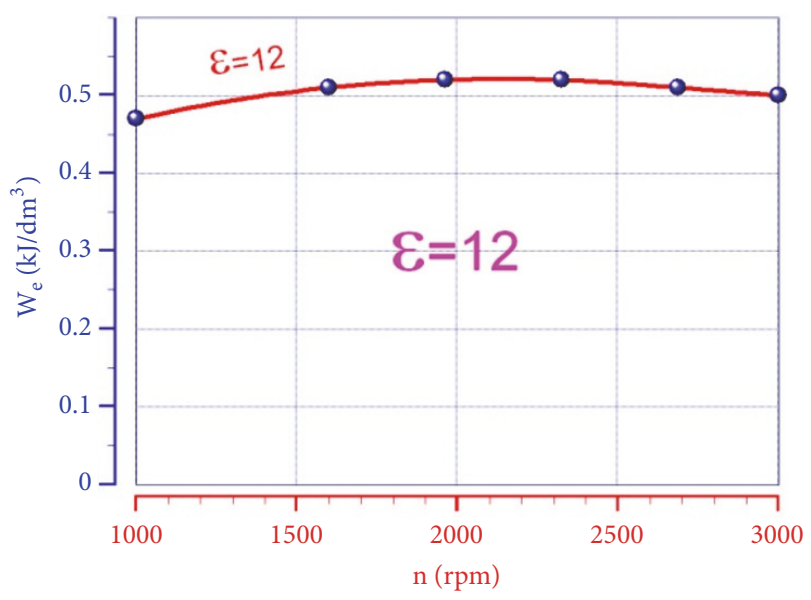

FIGURE 13: Selection of the optimal value of the (CR) for engine operating with the minimal PM emission.

load increase, this effect is attenuated and a certain decrease in (PM) emission occurs, so that, under large loads, it would begin to increase again. Because of the combustion chamber volume increases if the CR decreases; thus the amount of air in the cylinder increases, and it is the cause of decreasing of (PM) emission when the CR decreases [5].

Analysis of universal diagrams shows that the trends of (CR) variation are almost equal for the same values of fuel consumption and emission. Optimal $\left(\mathrm{NO}_{\mathrm{x}}\right)$ emission is achieved by later injection, while the minimal consumption and PM are achieved by earlier injection.

The multiple injection strategies in combination with EGR offer the potential to improve the compromise between engine emissions, noise, and fuel economy at diesel engines with lower CR.

\section{Conclusion}

The following generalized conclusions can be written from the study performed during experimental work and presented modelling: 
(i) VCR engine offers the potential to increase combustion efficiency and decrease emissions under varying load and speed conditions;

(ii) A good agreement between the model and experimental combustion law of the characteristic shape developed precisely at direct injection diesel engines is achieved by modeling with double Vibe function;

(iii) Initial combustion angle $\alpha_{\mathrm{ps}}$ intensively increases with the increase of the compression ratio due to shorter period of ignition delay, which is a consequence of higher temperatures at the moment of fuel injection;

This investigation has shown that the duration angle of the explosive combustion part is nearly constant and this value remained the same during modeling. Total combustion duration angle increases with the increase of the compression ratio, because the combustion is of higher quality and equally divided through all stages;

(iv) The amount of the fuel burnt at the first stage significantly decreases with the increase of the compression ratio, by constant amount of injected fuel and constant engine speed. This is also connected to shorter duration of ignition delay at higher compression ratios;

(v) Value of optimal compression ratio at which the engine runs with minimal fuel consumption increases with the increase of load. At full load, the fuel consumption is the smallest at maximal compression ratio of 17.5, while at low loads, minimal fuel consumption is achieved for compression ratio 12;

(vi) Under lower compression ratio of 12.1 the engine was started with much difficulty, and operation continued with higher knocking; and

(vii) From the aspect of minimal $\mathrm{NO}_{\mathrm{x}}$ emission, optimal compression ratio at full load has a value of 15 . Particles emission is the smallest for medium loads and increases if the engine runs at low or high loads. At the same time, particles emission increases with the increase of the compression ratio, so the optimal compression ratio is 12 .

\section{Data Availability}

The data used to support the findings of this study are available from the corresponding author upon request.

\section{Conflicts of Interest}

The authors declare that there are no conflicts of interest regarding the publication of this paper.

\section{Acknowledgments}

This paper is a result of the researches within the Project TR35041 financed by the Ministry of Science and Technological Development of the Republic of Serbia.

\section{References}

[1] S. Milojevic, "Reconstruction of existing city buses on diesel fuel for drive on Hydrogen," Applied Engineering Letters, vol. 1, no. 1, pp. 16-23, 2016.

[2] J. Schommers, H. Scheib, M. Hartweg, and A. Bosler, "Minimising Friction in Combustion Engines," MTZ worldwide, vol. 74, no. 7-8, pp. 28-35, 2013.

[3] R. B. Pešić, S. T. Milojević, and S. P. Veinović, "Benefits and challenges of variable compression ratio at diesel engines," Thermal Science, vol. 14, no. 4, pp. 1063-1073, 2010.

[4] R. Pesic and S. Milojevic, "Efficiency and ecological characteristics of a VCR diesel engine," International Journal of Automotive Technology, vol. 14, no. 5, pp. 675-681, 2013.

[5] S. Milojevic, "Analyzing the Impact of Variable Compression Ratio on Combustion Process in Diesel Engines," in Thesis, University of Kragujevac Faculty of Mechanical Engineering, Kragujevac, Serbia, 2005.

[6] R. Pešić, "ASMATA - Automobile Steel Material Parts Substitution with Aluminum," Mobility \& Vehicle Mechanics, vol. 30, pp. $1-165,2004$.

[7] A. Vencl, A. Rac, and I. Bobić, "Tribological behaviour of Albased MMCs and their application in automotive industry," Tribology in Industry, vol. 26, no. 3-4, pp. 31-38, 2004.

[8] S. Velickovic, S. Garic, B. Stojanovic, and A. Vencl, "Tribological Properties of Aluminium Matrix Nanocomposites," Applied Engineering Letters, vol. 1, no. 3, pp. 72-79, 2016.

[9] Y. B. Mathur, M. P. Poonia, A. S. Jethoo, and R. Singh, "Optimization of Compression Ratio of Diesel Fuelled Variable Compression Ratio Engine," International Journal of Energy Engineering, vol. 2, no. 3, pp. 99-101, 2012.

[10] A. G. Reddy, "Effect of Compression Ratio on the Performance of Diesel Engine at Different Loads," International Journal of Engineering Research and Applications, vol. 5, no. 10, pp. 62-68, 2015.

[11] K. Stricker, L. Kocher, E. Koeberlein, D. Van Alstine, and G. M. Shaver, "Estimation of effective compression ratio for engines utilizing flexible intake valve actuation," Proceedings of the Institution of Mechanical Engineers, Part D: Journal of Automobile Engineering, vol. 226, no. 8, pp. 1001-1015, 2012.

[12] N. Gajarlawara, G. A. P. Rao, and M. K. Murthy, "Experimental investigations of effects of cooling/non cooling of EGR on two level of compression ratio in a common rail diesel engine," Thermal Science, vol. 19, no. 6, pp. 1995-2002, 2015.

[13] N. Gajarlawar, A. Khetan, and G. A. P. Rao, "Investigations of effects of pilot injection with change in level of compression ratio in a common rail diesel engine," Thermal Science, vol. 17, no. 1, pp. 71-80, 2013.

[14] S. Ahn, J. Park, J. Won et al., "An analytical FEM-based study of the drawing process of an ultra-high-pressure common-rail fuel tube," Journal of Mechanical Science and Technology, vol. 31, no. 7, pp. 3389-3396, 2017.

[15] J. Hirkude and A. S. Padalkar, "Experimental investigation of the effect of compression ratio on performance and emissions of CI engine operated with waste fried oil methyl ester blend," Fuel Processing Technology, vol. 128, pp. 367-375, 2014.

[16] S. Sheeju Selva Roji, R. Edwin Raj, and D. F. Melvin Jose, "Experimental evaluation of performance and emission characteristics of a diesel engine fuelled with neem methyl ester," Transactions of FAMENA, vol. 40, no. 3, pp. 81-90, 2016.

[17] R. Kumar and A. K. Dixit, "Combustion and Emission Characteristics of Variable Compression Ignition Engine Fueled with 
Jatropha curcas Ethyl Ester Blends at Different Compression Ratio," Journal of Renewable Energy, vol. 2014, Article ID 872923, 12 pages, 2014.

[18] S. S. S. Roji, R. E. Rajb, D. M. Jose, and Z. R. Kennedy, "Effect of compression ratio with biodiesel and its blends on performance and emission characteristics of an IC engine," Journal of Environmental Protection and Ecology, vol. 16, no. 2, pp. 601-609, 2015.

[19] T. S. Hora and A. K. Agarwal, "Effect of varying compression ratio on combustion, performance, and emissions of a hydrogen enriched compressed natural gas fuelled engine," Journal of Natural Gas Science and Engineering, vol. 31, pp. 819-828, 2016.

[20] K. Duffy, A. Kieser, P. Mehresh et al., "Heavy Duty HCCI Development Activities, DOE DEER Conference - DOE Contract DE-FC26-05NT42412," in Proceedings of the Heavy Duty HCCI Development Activities , DOE DEER Conference - DOE Contract DE-FC26-05NT42412, p. 25, 2006.

[21] S. Pischinger, K. Wittek, and C. Tiemann, "Two-stage Variable Compression Ratio with Eccentric Piston Pin," MTZ worldwide, vol. 70, no. 2, pp. 20-27, 2009.

[22] V. Collée, C. Constensou, F. Dubois, and L. Guilly, "Variable Compression Ratio for Future Emission Standards," MTZ worldwide, vol. 78, no. 4, pp. 52-57, 2017.

[23] U. Schlemmer-Kelling, S. Ghetti, P. Methfessel, and C. Marten, "Variable Compression for Large Engine," MTZ worldwide, vol. 78, no. 7-8, pp. 50-55, 2017.

[24] J. I. Ghojel, "Review of the development and applications of the Wiebe function: A tribute to the contribution of Ivan Wiebe to engine research," International Journal of Engine Research, vol. 11, no. 4, pp. 297-312, 2010.

[25] S. Jindal, B. P. Nandwana, N. S. Rathore, and V. Vashistha, "Experimental investigation of the effect of compression ratio and injection pressure in a direct injection diesel engine running on Jatropha methyl ester," Applied Thermal Engineering, vol. 30, no. 5, pp. 442-448, 2010. 


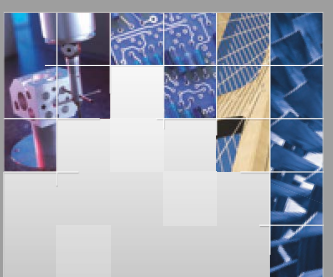

\section{Enfincering}
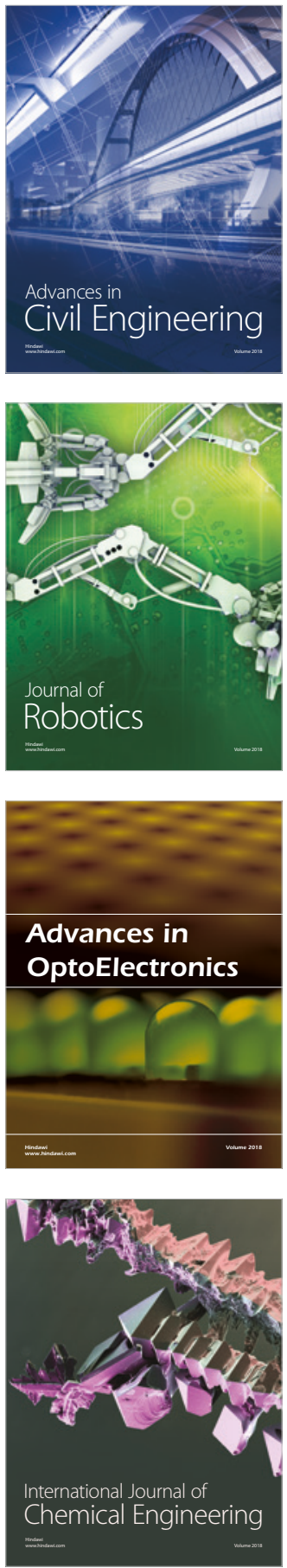

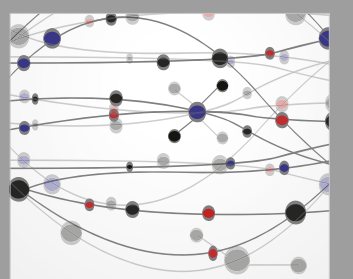

\section{Rotating \\ Machinery}

The Scientific World Journal

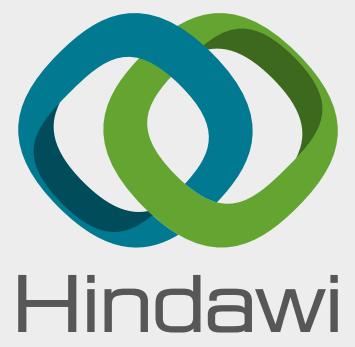

Submit your manuscripts at

www.hindawi.com
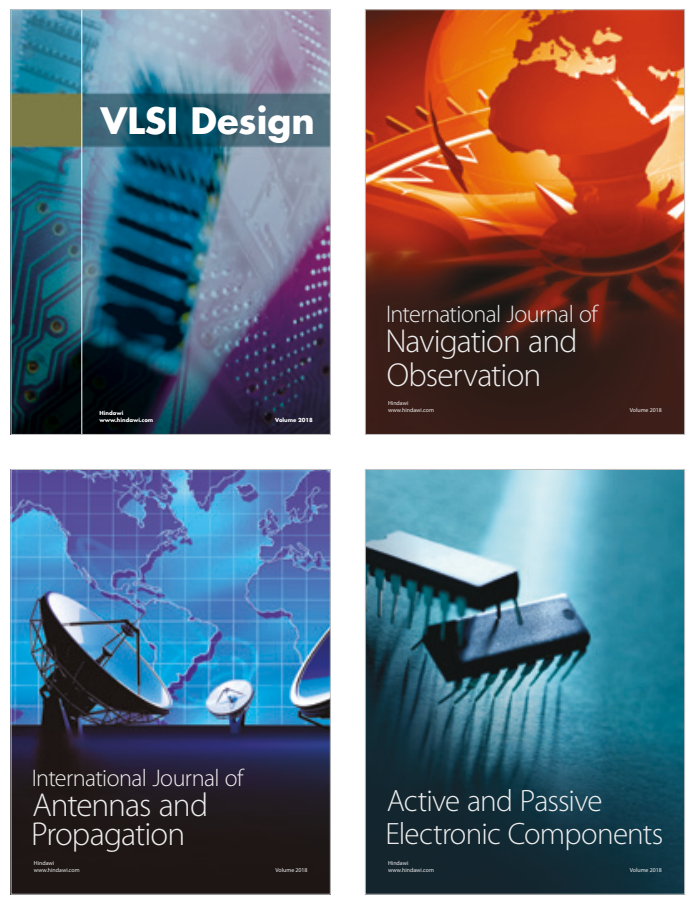
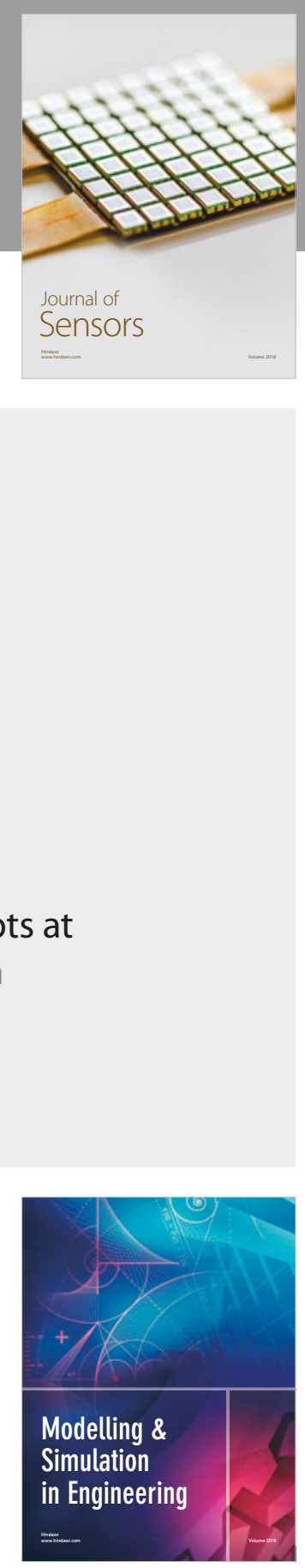

\section{Advances \\ Multimedia}
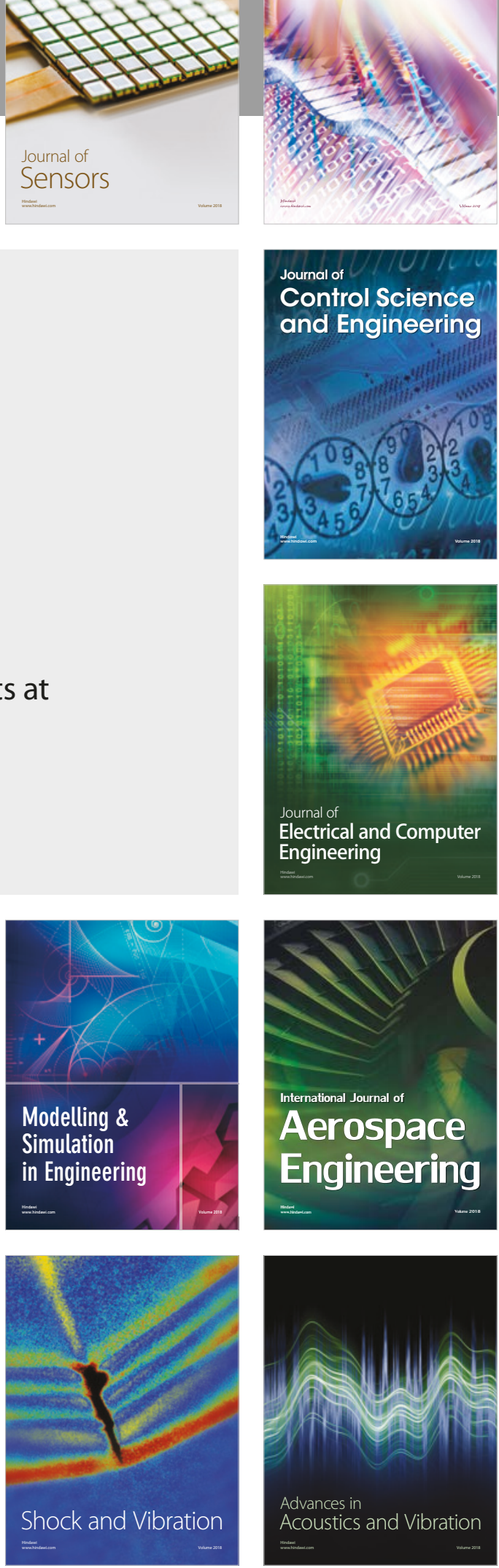